\title{
Avaliação histológica e histomorfométrica da regeneração óssea a partir da utilização de biomateriais em tíbias de ovinos ${ }^{1}$
}

\author{
Nicole F. Paretsis ${ }^{2 *}$, Victor E. Arana-Chavez ${ }^{3}$, Luciana Correa ${ }^{4}$, Ana Maria G. Peplis ${ }^{5}$, \\ Virginia C.A. Martins ${ }^{5}$, Silvia R.G. Cortopassi ${ }^{6}$ e André L.V. Zoppa ${ }^{6}$
}

\begin{abstract}
Paretsis N.F., Arana-Chavez V.E., Correa L., Peplis A.M.G., Martins V.C.A., Cortopassi S.R.G. \& Zoppa A.L.V. 2017. [Histological and histomorphometric evaluation of bone regeneration with biomaterial in the tibia of sheep.] Avaliação histológica e histomorfométrica da regeneração óssea a partir da utilização de biomateriais em tíbias de ovinos. Pesquisa Veterinária Brasileira 37(12):1537-1544. Departamento de Cirurgia, Faculdade de Medicina Veterinária e Zootecnia, Universidade de São Paulo, Av. Prof. Orlando Marquês de Paiva 87, Butantã, São Paulo, SP 0558-270, Brazil. E-mail: nicoleparetsis@gmail.com

Bone defects are commonly found in veterinary medicine through different disease such as trauma, especially in large animals. Frequently it is necessary to assist this tissue repair for better regeneration. Biomaterials in general are designed to this function. In order to understand the bone cells in the presence of bone substitutes, tests in vivo are essential for these studies. The quantity and quality of new tissue formation can be assessed by observation of tissue morphofunctional unit. Currently, in orthopedic studies sheep are considerated animals of choice for experimental development. Bone defects were performed experimentally in sheep and were implanted chitosan, hydroxyapatite and collagen biomaterials. After 60 days, biopsy was performed at the site of tissue repair and the new tissue formation was described, evaluated and compared by organic matrix bone histomorphometry and electronic transmission microscopy. After hystomorfometry analysis there was no difference between control group and biomaterial group, but when compare with pre-existent tissue, the values are smaller. In descriptive analysis was observed intimate contact with biomaterial and new tissue formation suggesting biocompatibility. It observed the pattern of tissue repair in control group and biomaterial group did not differ in the architecture tissue. However, in the biomaterial group was identified presence of the biomaterial in the specimen. All these data suggest that the biomaterial did not impair bone regeneration, had good biocompatibility and potential to assistant in orthopedic routine of large animals.
\end{abstract}

INDEX TERMS: Histomorphometry, histology, bone regeneration, biomaterial, tibia, sheep, hydroxyapatite, chitosan, collagen, orthopedics.

\footnotetext{
${ }^{1}$ Recebido em 26 de agosto de 2016.

Aceito para publicação em 21 de junho de 2017.

${ }^{2}$ Departamento de Cirurgia, Universidade de São Paulo (USP), Avenida Prof. Orlando Marquês Paiva 87, Butantã, São Paulo, SP 05508-270, Brasil. Pesquisa de mestrado com apoio FAPESP. *Autor para correspondência: nicoleparetsis@gmail.br

${ }^{3}$ Laboratório de Biologia Oral, Faculdade de Odontologia, USP, Avenida Prof. Lineu Prestes 2227, Cidade Universitária, São Paulo, SP 05508-000, Brasil.

${ }^{4}$ Laboratório de Patologia Experimental, Faculdade de Odontologia, USP, Avenida Prof. Lineu Prestes 2227, Cidade Universitária, São Paulo, SP 05508-000, Brasil.

${ }^{5}$ Instituto de Química de São Carlos (IQSC), Av. Trab. São-Carlense 400, Parque Arnold Schmidt, São Carlos, SP 13566-590, Brasil.

${ }^{6}$ Departamento de Cirurgia, USP, Av. Prof. Orlando Marquês Paiva 87, Butantã, São Paulo, SP 05508-270, Brasil.
}

RESUMO.- Falhas ósseas são comumente encontradas na medicina veterinária em diferentes enfermidades, principalmente por traumas em grandes animais. Frequentemente faz-se necessário auxiliar este reparo tecidual para melhor correção desta falha. Os biomateriais foram desenvolvidos para cumprir esta função. A fim de avaliar o comportamento celular perante estes substitutos ósseos, a realização de testes in vivo é fundamental. A partir da observação da unidade morfofuncional do tecido é possível avaliar a quantidade e a qualidade do tecido neoformado. Atualmente, em estudos ortopédicos, os ovinos são considerados animais de escolha como modelo experimental. Falhas ósseas foram realizadas experimentalmente em ovinos, onde foram implantados biomateriais à base de 
quitosana, hidroxiapatita e colágeno. Após 60 dias foi realizada biopsia no local do reparo tecidual e por meio da histomorfometria da matriz orgânica, da análise descritiva da microscopia de luz e da microscopia eletrônica de transmissão, o tecido neoformado foi avaliado e comparado. $\mathrm{Na}$ histomorfometria, não houve diferença significativa quanto à quantidade de tecido neorformado do grupo controle $\mathrm{e}$ do grupo com biomaterial, porém quando comparado ao osso pré-existente, retirado no momento da confecção da falha, a área de matriz óssea foi menor. Na descrição da microscopia de luz e em maiores detalhes na análise ultra estrutural, observou-se o biomaterial em contato íntimo com o tecido neoformado, sugerindo boa biocompatibilidade. Foi possível observar o padrão da reparação tecidual, onde o membro controle e o membro com biomaterial não diferiram quanto à arquitetura tecidual, porém nas amostras com o implante do biomaterial foi identificada a presença do mesmo. Todas estas informações sugerem que o biomaterial não prejudicou a regeneração óssea, apresentou boa biocompatibilidade e denota potencial para auxiliar na rotina ortopédica de grandes animais.

TERMOS DE INDEXAÇÃO: Histomorfometria, histologia, regeneração óssea, biomaterial, tíbia, ovino, hidroxiapatita, quitosana, colágeno, ortopedia.

\section{INTRODUÇÃO}

Os substitutos ósseos na medicina já apresentam aplicabilidade clínica em diversas áreas, entretanto, na medicina veterinária, esta ferramenta não é rotineiramente utilizada. Experimentalmente, diversos estudos são realizados visando a reparação óssea de diferentes espécies (Dornbusch et al. 2010, Milori et al. 2013, Marcondes 2014, Nóbrega 2014, Almeida 2015).

Nos últimos anos os ovinos vêm sendo utilizados para este propósito, sendo considerado modelo valioso para estudar atividade e remodelação óssea (Martini et al. 2001, Pearce et al. 2007). A reparação do tecido ósseo deve manter a integridade e a homeostase do órgão. Este evento é fortemente coordenado, sincronizado e requer a participação de diversas células para assegurar a preservação da massa óssea (Raggatt \& Partridge 2010).

0 uso dos biomateriais inclui desde a avaliação clínica geral do animal até suas propriedades sobre o tecido. Histologicamente, o ideal é que os biomateriais sejam osteocondutores onde conseguem promover a aposição de tecido ósseo em sua superfície, funcionando como um molde que facilite sua neoformação. Outras características fundamentais são a biocompatibilidade e a osteointegração, esta última, definida como uma ancoragem direta de um implante pela formação de tecido ósseo ao redor, sem a presença de tecido fibroso na interface osso-implante (Dornbusch et al. 2010).

A hidroxiapatita faz parte de um grupo de minerais chamado apatitas, e possui a fórmula química $\mathrm{Ca}_{10}\left(\mathrm{PO}_{4}\right)_{6}(\mathrm{OH})_{2}$ (Amaral 2006, Gutierres et al. 2006). 0 uso da hidroxiapatita como biomaterial tem sido pesquisado desde 1970 e é bastante documentado na literatura (Vital et al. 2006, Carlo et al. 2007). As hidroxiapatitas de origem sintética ou natural apresentam semelhança estrutural, química e física com a matriz mineral óssea (Dantas et al. 2011). Esta apatita tem sido apresentada e comercializada em diversas formas, como cerâmicas, com consistências densas ou porosas, blocos e grânulos e continua sendo objeto de estudos em diferentes porosidades (Martins et al. 2010) e associações (Reis et al. 2010).

A quitosana é um biopolímero hidrófilo obtido a partir de quitina, o segundo polissacarídeo mais abundante na natureza. Sua principal fonte natural é carapaça de crustáceos (Spin-Neto et al. 2012, Dias et al. 2013, Tavakol et al. 2013). Nos últimos anos, o interesse em utilizar a quitosana como biomaterial aumentou de forma significativa, o que expressa grande número de artigos científicos relacionados com sua caracterização e testes em geral (Danilchenko et al. 2011, Tavakol et al. 2013). No entanto, a quitosana sozinha não é considerada material ideal para a reparação tecidual, uma vez que sua bioatividade não é eficaz e precisa ser melhorada por meio da combinação com outros compósitos (Tavakol et al. 2013). Quando associada à hidroxiapatita, tende a apresentar boa osteocondução (Nandi et al. 2010).

O colágeno, utilizado como biomaterial, apresenta importantes características, como baixo índice de irritabilidade ou alogenicidade, boa biodegradabilidade, biocompatibilidade, agente hemostático, habilidade em promover crescimento celular e susceptibilidade às modificações químicas (Amaral 2006). 0 colágeno como biomaterial também é conhecido por apresentar propriedades osteoindutoras (Babiker 2013) que podem ser potencializadas quando associadas à hidroxiapatita ou fosfato tricálcio (Nandi et al. 2010). Além disso, o colágeno participa no controle da estrutura do tecido a ser formado (Shirane et al. 2010). Como biomaterial, pode ser apresentado em diversas formas, como esferas, membranas (Pettian et al. 2014) e géis injetáveis (Goissis \& Góes 1997).

0 biomaterial utilizado neste experimento foi testado in vitro e in vivo em animais de laboratório no qual não foi observado toxicidade celular. Notou-se resposta inflamatória discreta e permitiu crescimento tecidual favorável (Amaral 2006). 0 objetivo deste trabalho é descrever e caracterizar histologicamente o tecido neoformado descalcificado, de forma qualitativa e quantitativa na presença do biomaterial composto de quitosana, colágeno e hidroxiapatita, a partir de falhas ósseas induzidas experimentalmente na tíbia de ovinos, e compará-lo com o membro contralateral (membro controle). Considerando todas as propriedades da matéria-prima deste biomaterial, a hipótese deste experimento é que este biomaterial apresente biocompatibilidade, a quantidade de matriz orgânica seja igual ou maior das amostras com o biomaterial e a arquitetura tecidual seja semelhante ao controle.

\section{MATERIAL E MÉTODOS}

O estudo foi aprovado pela Comissão de Ética no Uso de Animais, Faculdade de Medicina Veterinária e Zootecnia (FMVZ), Universidade de São Paulo (USP) sob o protocolo no. 7693230914.

Biomaterial. 0 compósito utilizado foi produzido na Faculdade de Medicina de Ribeirão Preto e no Instituto de Química de São Carlos da Universidade de São Paulo. A hidroxiapatita foi obtida através da desproteinização de osso bovino. A matéria-prima utilizada para extrair o colágeno foi tendão de origem bovina e a quitosana foi obtida a partir do gládio de lula. As matrizes foram 
feitas com solução de quitosana 1\% e gel de colágeno $1 \%$ na proporção 1:3, respectivamente, homogeneizando-se por agitação mecânica. Após essa homogeneização adicionou-se hidroxiapatita na proporção 6:1, homogeneizando-se novamente. Cada cilindro foi obtido por $0,6 \mathrm{~g}$ do material formado e colocado em molde, congelado e liofilizado. 0 material foi neutralizado em solução de $\mathrm{NaHCO}_{3}$, seguido de lavagens com água desionizada, com posterior congelamento e liofilização.

Animais. Foram utilizados seis ovinos, fêmeas, adultas, da raça Santa Inês, com $32 \pm 6 \mathrm{~kg}$. Durante o estudo, os animais foram mantidos em regime de estabulação (dois animais por baia) no Serviço de Cirurgia de Grandes Animais no Hospital Veterinário da FMVZ-USP, com dieta de feno de tifton e água à vontade, e alimento concentrado comercial peletizado na proporção de $1 \%$ do peso vivo. Após a chegada, os animais foram identificados, vacinados contra clostridioses ${ }^{7}$ e foram realizados exames laboratoriais (hemograma completo, perfil hepático e perfil renal) a fim de certificar a sanidade destes animais. Os ovinos também foram vermifugados com moxidectina ${ }^{8}$ ou levamisol $^{9}$.

Os animais foram submetidos a anestesia geral inalatória, após 48 horas de jejum alimentar e 8 horas de jejum hídrico, seguindo o seguinte protocolo: medicação pré-anestésica com cloridrato de xilazina ${ }^{10}(0,05 \mathrm{mg} / \mathrm{kg}$, por via intravenosa), indução anestésica com propofol ${ }^{11}(6 \mathrm{mg} / \mathrm{kg}$, por via intravenosa), manutenção da anestesia com isoflurano ${ }^{12}$ vaporizado em oxigênio $100 \%$ por meio de intubação com sonda orotraqueal. Em seguida, os animais foram preparados para procedimento cirúrgico por meio de antissepsia.

Após posicionamento em decúbito lateral para o procedimento, o acesso à área escolhida foi localizado entre cinco e sete centímetros, na face medial, distal ao côndilo medial da tíbia. Para confirmar o local do procedimento, após as mensurações com régua sobre o membro, foram realizadas projeções radiográficas ${ }^{13}$ lateromedial, em cada animal, com agulha posicionada indicando a região de interesse. Realizou-se incisão semilunar de pele e subcutâneo de aproximadamente quatro centímetros, até a exposição do periósteo da tíbia. Realizou-se incisão do periósteo com o mesmo formato da incisão de pele, e elevação do mesmo até a exposição parcial da superfície óssea.

Com dimensão de cinco milímetros de diâmetro, a falha foi realizada utilizando serra trefina acoplada a perfuradora elétri$\mathrm{ca}^{13}$, sob irrigação contínua com solução de $\mathrm{NaCl}$ 0,9\% (Fig.1A). A profundidade da falha foi determinada individualmente, sendo o limite a transposição completa da cortical-cis de cada animal, e em seguida foi implantado o biomaterial. 0 biomaterial pôde ser moldado para preencher toda a falha óssea devido sua apresentação e consistência (Fig.1B e Fig.2). 0 implante foi recoberto pelo periósteo e subcutâneo, que foi suturado com fio poliglecaprone 25 no 2.0, padrão de sutura simples contínuo. A síntese de pele foi feita com fio nylon no2.0, em padrão simples separado. Após procedimento em um membro, foi seguido o mesmo protocolo para confecção da falha no membro contralateral, que foi considerado controle de remodelamento, sem preenchimento com o biomaterial. $\mathrm{O}$ fragmento ósseo retirado no momento da confecção da falha foi fragmentado em duas partes iguais e submetido às análises histológicas e histomorfométricas para comparação da regeneração óssea, com os fragmentos coletados nas biopsias.

Após 60 dias, os animais foram submetidos à anestesia geral com o mesmo protocolo já citado, e foram realizadas duas biopsias ósseas de 3,5mm, com o uso de serra trefina acoplada a perfuradora elétrica ${ }^{13}$, sob irrigação contínua com solução de $\mathrm{NaCl}$ $0,9 \%$, na interface entre osso/implante e osso/tecido neoformado, em cada membro, para as análises histológicas.

Desta forma, foram estabelecidos três grupos: Grupo controle - apenas a falha óssea, sem o biomaterial; Grupo Biomaterial - fa-
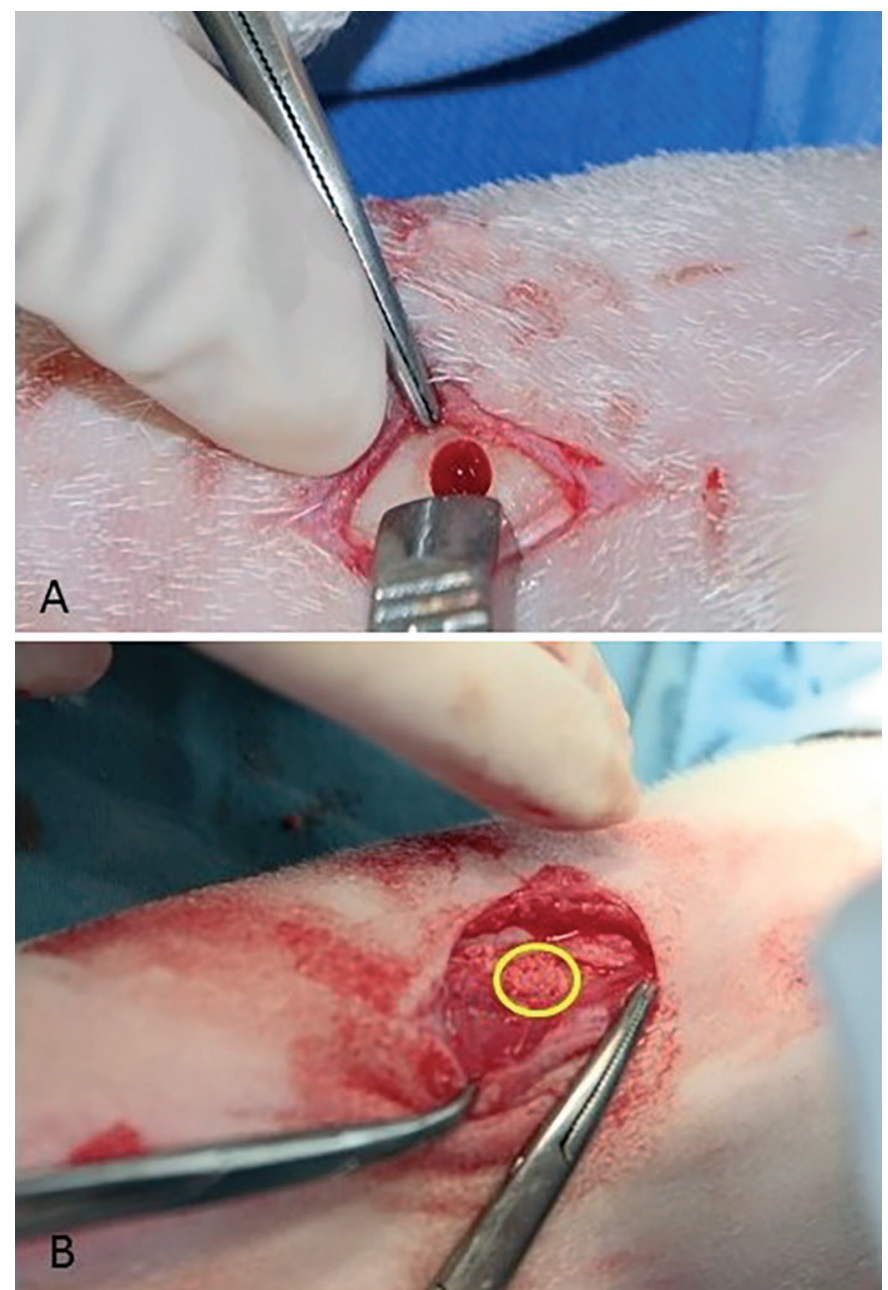

Fig.1. (A) Defeito ósseo em tíbia de ovino na face medial do membro, com diâmetro de $5 \mathrm{~mm}$ sem preenchimento (membro controle); (B) Defeito ósseo em tíbia de ovino na face medial do membro com diâmetro de $5 \mathrm{~mm}$ preenchido com biomaterial (circunferência amarela).

lha preenchida pelo biomaterial; Grupo Confecção - tecido ósseo sadio presente no local da falha, obtido no momento desta.

No período pós-operatório foram realizados exames físicos diários no qual foram aferidas frequência cardíaca, frequência respiratória, temperatura transretal e movimentos ruminais. À inspeção, os ovinos foram avaliados quanto apetite, ruminação e presença ou ausência de claudicação. A ferida cirúrgica foi higienizada com solução fisiológica até a retirada dos pontos, que ocorreu no $10^{\circ}$ dia após o procedimento cirúrgico. Foi administrado em todos os ovinos cloridrato de amicacina ${ }^{14}(25 \mathrm{mg} / \mathrm{kg}$, por via intravenosa, uma vez ao dia, por 5 dias), cloridrato de tramadol ${ }^{15}$

\footnotetext{
${ }^{7}$ Sintoxan Polivalente T ${ }^{\circledR}$, Merial Saúde Animal, Paulínia/SP, Brasil;

${ }^{8}$ Ripercol $^{\circledR}$, Fort Dodge, Campinas/SP, Brasil;

${ }^{9}$ Cydectin Injetável Ovinos ${ }^{\circledR}$, Fort Dodge, Campinas/SP, Brasil;

${ }^{10}$ Rompum $^{\circledR}$, Bayer Saúde Animal, São Paulo/SP, Brasil;

${ }^{11}$ Propovan $^{\circledR}$, Cristália, Itapira/SP, Brasil;

${ }^{12}$ Isoforine $^{\circledR}$, Cristália, Itapira/SP, Brasil;

${ }^{13}$ Sound Eklin Mark 2, Carlsbad/CA, Estados Unidos;

${ }^{13}$ TRS Modular Drive ${ }^{\circledR}$, Synthes ${ }^{\circledR}$, Solna, Suíça;

${ }^{13}$ TRS Modular Drive ${ }^{\circledR}$, Synthes ${ }^{\circledR}$, Solna, Suíça.

${ }^{14}$ Sulfato de Amicacina ${ }^{\circledR}$, Neofarma, Anápolis/GO, Brasil;

${ }^{15}$ Tramadol, Cristália, Itapira/SP, Brasil;
} 


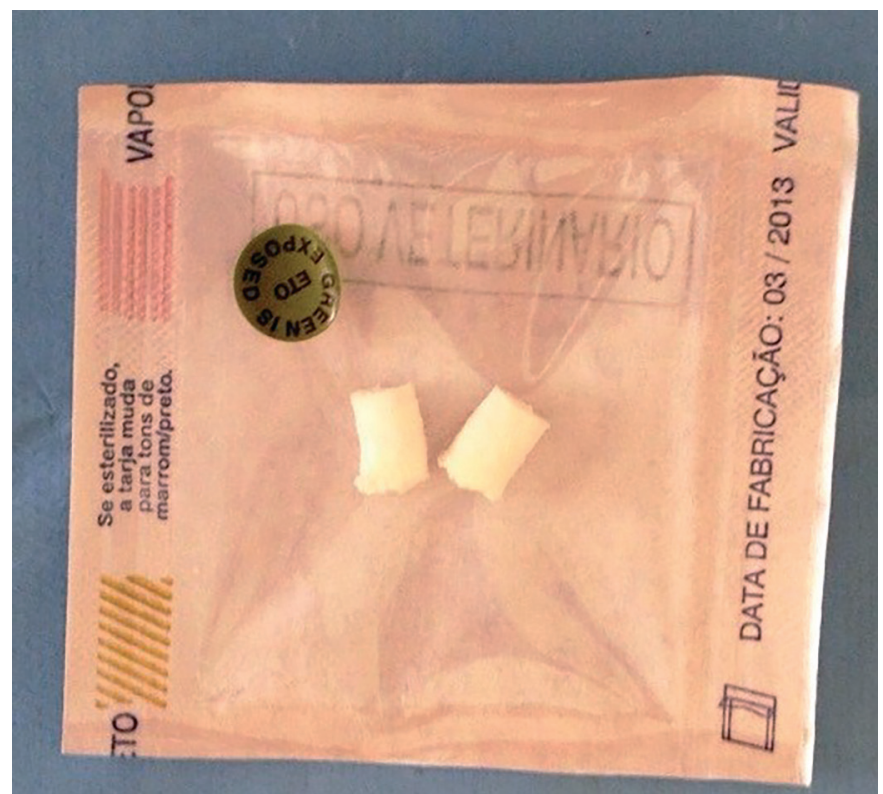

Fig.2. Biomaterial à base de hidroxiapatita, colágeno e quitosana, já embalado e esterilizado, pronto para aplicação.

( $3 \mathrm{mg} / \mathrm{kg}$, por via intravenosa, duas vezes ao dia, por 3 dias), fenilbutazona ${ }^{16}(4 \mathrm{mg} / \mathrm{kg}$, por via intravenosa, uma vez ao dia, por 3 dias) e cloridrato ranitidina ${ }^{17}(2 \mathrm{mg} / \mathrm{kg}$, por via intravenosa, uma vez ao dia, por 3 dias). Ainda no pós-operatório foram realizadas imagens radiográficas quinzenais com o objetivo de observar a integridade do membro e evolução das falhas ósseas. Após a realização das biopsias, os animais foram recuperados, examinados e inspecionados seguindo o mesmo protocolo de antibioticoterapia e analgesia citado no pós-operatório da confecção da falha.

Microscopia de luz e histomorfometria. Todos os 11 fragmentos ósseos foram identificados, lavados com solução fisiológica e fixados com solução de paraformaldeído à $20 \%$ e tampão de fosfato de sódio por 48 horas, descalcificados em solução com EDTA a 10\%, pH 7,4 por aproximadamente 90 dias e incluídos em paraplast ${ }^{18}$. Foram realizados diversos cortes de $5 \mu \mathrm{m}$ das amostras utilizando micrótomo ${ }^{19}$. Os cortes foram corados com hematoxilina e eosina (HE) e tricômico de Masson, e as imagens foram analisadas e descritas.

Para a aquisição de imagens foi realizada a varredura com área de fração de $1370279 \mu^{2}$ registrando o número máximo de campos dentro de cada corte sem artefatos, utilizando lentes oculares de $10 \mathrm{x}$, fotomicrografadas com o auxílio software ${ }^{20}$ e posteriormente analisadas em outro software ${ }^{21}$. As porcentagens de matriz óssea nas amostras do fragmento removido inicialmente e nas amostras obtidas por biopsia após 60 dias, no controle e biomaterial, foram comparadas.

Análise estatística. Nos ensaios de histomorfometria, os dados de área de tecido ósseo foram apresentados em porcentagem. Adotou-se como estatística descritiva média, mediana e valores

\footnotetext{
${ }^{16}$ Equipalazone Injetável ${ }^{\circledR}$, Marcolab, Duque de Caxias/RJ, Brasil;

${ }^{17}$ Cloridrato de Ranitidina ${ }^{\circledR}$, Novafarma, Anápolis/GO, Brasil;

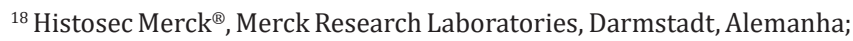

${ }^{19}$ Spencer $820^{\circledR}$, American Optical Corpotation, Estados Unidos;

${ }^{20}$ Leica, Leica Aplication Suite ${ }^{\circledR}$ (LAS V4,1), Alemanha;

${ }^{21}$ WCIF Image J $1.49 \mathrm{v}^{\circledR}$, National Institute of Health, Estados Unido;

${ }^{22}$ Eletron Microscopy Science, Hatfiled/PA, Estados Unidos;

${ }^{23}$ Leica Ultracut R, Leica, Wetzlar, Alemanha;

${ }^{24}$ JEOL 1010, JEOL, Tóquio, Japão;

${ }^{25} 4,5$ mm LCP Synthes ${ }^{\circledR}$, Solna, Suíça.
}

máximo e mínimo. Esses dados foram não-paramétricos. Para comparação entre os grupos, foi executado o teste de Kruskal-Wallis para comparações múltiplas, e de Mann-Whitney para comparações dois-a-dois. 0 nível de significância adotado foi de 5\%.

Microscopia eletrônica de transmissão. Onze fragmentos ósseos foram fixados a $4 \%$ de formaldeído e $0,1 \%$ de glutaraldeído, tamponado com cacodilato de sódio $0,1 \mathrm{M}$ e pH 7,2, descalcificados imersos em solução de EDTA a 4,13\%, pH 7,2, substituída a cada 48 horas. Este procedimento foi realizado por aproximadamente 90 dias. Após o período de descalcificação procedeu-se o corte no eixo longitudinal de cada amostra, e as porções obtidas foram destinadas ao processamento de inclusão em resina Spurr ${ }^{22}$.

Foram selecionadas e realizadas a trimagem das regiões de interface do biomaterial e tecido ósseo, para subsequentes cortes ultrafinos de $70 \mathrm{~nm}$ em um ultramicrótomo ${ }^{23}$. Os cortes foram colocados em telas de cobre de 200 meshes, contrastadas com uranila $2 \%$ e citrato de chumbo. As telas de cobre foram examinadas a fim de obter detalhes estruturais da interface do tecido ósseo e fotografadas no microscópio eletrônico de transmissão ${ }^{24}$ equipado com dispositivo de captura de imagem digital, operado a $80 \mathrm{kV}$.

\section{Animais}

\section{RESULTADOS}

Os exames físicos dos animais se mantiveram dentro dos padrões de normalidade, e embora estabulados a maior parte do tempo, não foi observado nenhum comportamento anormal, impotência funcional dos membros ou ausência de ruminação. Nos exames radiográficos, não foi encontrada nenhuma alteração da integridade do membro. Apenas um ovino sofreu acidente durante o período noturno e apresentou fratura completa em bisel na altura da falha, do membro controle (sem biomaterial), após 35 dias de pós-operatório. Este animal foi submetido à osteossíntese com placa de compressão bloqueada $\mathrm{LCP}^{25}$, durante todo o período pós-operatório da osteossíntese e excluído do experimento.

\section{Histomorfometria}

Quando comparada a porcentagem de quantidade de matriz óssea do Grupo Biomaterial com o Controle, não foram observadas diferenças significativas $(\mathrm{p}=0.176)$, porém quando o Grupo Biomaterial foi comparado com o Grupo Confecção, a quantidade de matriz óssea foi menor no Grupo Biomaterial ( $\mathrm{p}<0.001)$ (Fig.3).

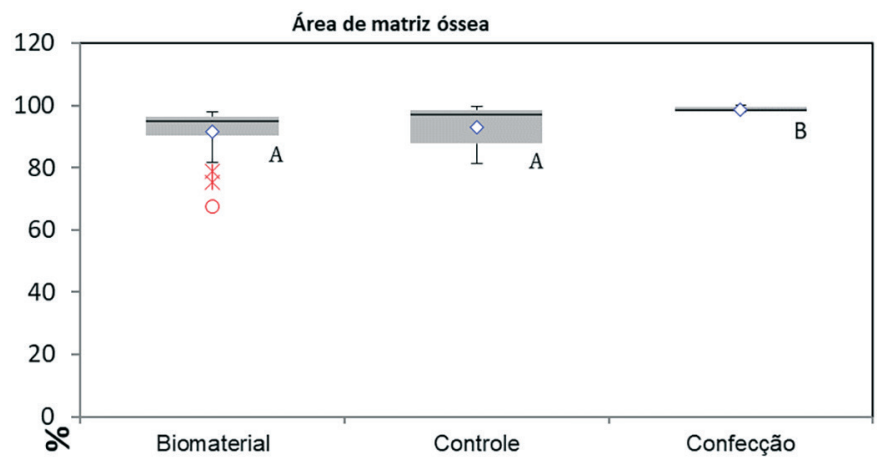

Fig.3. Comparação da porcentagem da área de matriz óssea das amostras com biomaterial (compósito), controle e da amostra retirada no momento da confecção da falha óssea. o, $*=o u-$ tliers; $\diamond=$ média; $-=$ mediana. Letras diferentes indicam diferenças estatisticamente significantes entre os grupos. 

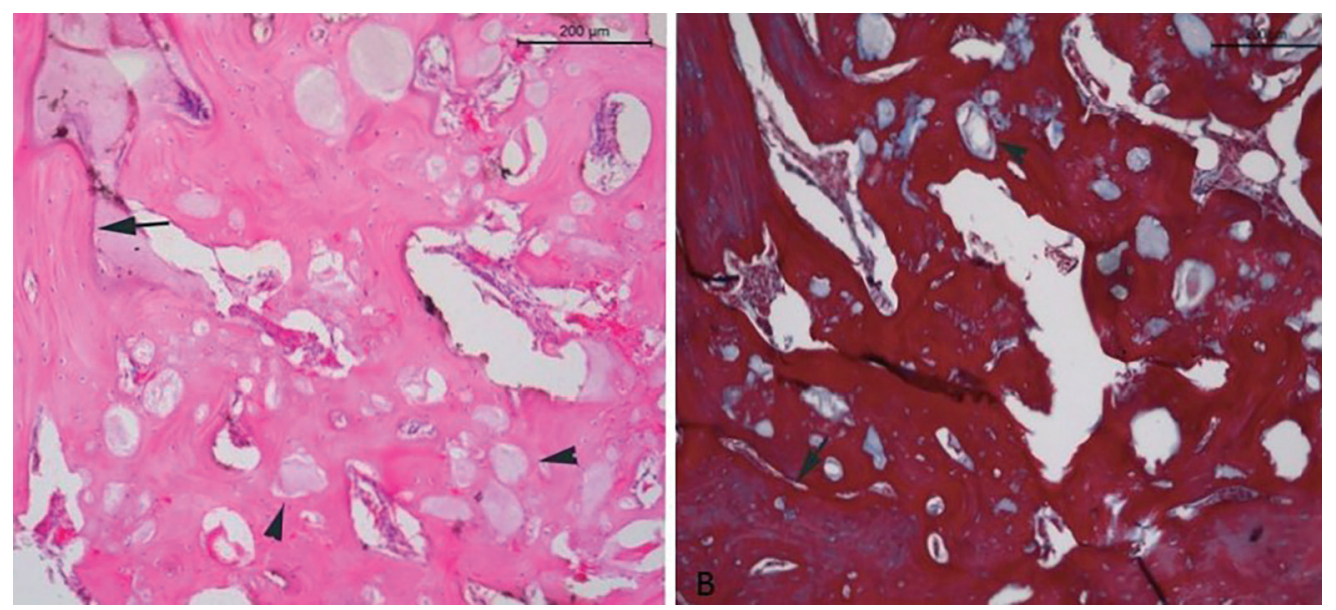

Fig.4. (A) Corte histológico em coloração hematoxilina e eosina em que se nota a presença de material exógeno (cabeça de seta preta) envolvido por matriz óssea no tecido ósseo neoformado. É evidente o limite desse tecido com o osso pré-existente (seta preta). HE, obj.10x. (B) Corte histológico em tricrômico de Masson que se nota a presença de material exógeno (cabeça de seta preta), de coloração azulada, envolvido por matriz óssea em tecido ósseo neoformado. 0 limite desse tecido com o osso pré-existente (seta preta) também é observado. Obj.10x.

\section{Análise descritiva microscopia de luz}

Nas amostras que continham biomaterial, os cortes histológicos evidenciaram fragmento de tecido ósseo compacto exibindo matriz envolvendo material exógeno, de aspecto fibrinóide e coloração eosinofílica pálida na coloração em hematoxilina e eosina, e azul na coloração por tricrômico de Masson, compatível com biomaterial (Fig.4). 0 tecido ósseo neoformado exibiu espaços medulares por vezes amplos, com tecido conjuntivo frouxo e tecido adiposo em seu interior. Em áreas focais foi possível visualizar células gigantes multinucleadas exibindo o material exógeno em seu interior (Fig.5). Não houve presença de infiltrado inflamatório, nem de necrose.

\section{Microscopia eletrônica de transmissão}

$\mathrm{Na}$ amostra do defeito com o implante foi identificada presença do biomaterial entremeado à matriz óssea (Fig.6A). 0 osso primário formado encontrava-se em contato íntimo com o biomaterial de estudo (Fig.6B).

Foi observada imagem sugestiva de linhas ricas em proteínas não-colágenas envolvendo todo o biomaterial (Fig.6C). Em uma das amostras do membro com implante de biomaterial, foi identificado um ostéócito recém-formado, e em sua porção inferior, verificou-se um gap entre o biomaterial e o osteócito (Fig.6D). Quando esta porção inferior do mesmo osteócito foi examinada em maior aumento, foi notada presença de um canalículo entremeado à matriz, comprovando que o biomaterial não dificultou sua comunicação (Fig.6E). Observou-se, também, presença de fibrilas colágenas frouxamente dispostas, próximas ao biomaterial (Fig.6F).

\section{DISCUSSÃO}

Seguindo o que foi descrito por Paretsis et al. (2016), a falha óssea circular de cinco milímetros de diâmetro na tíbia foi escolhida devido à viabilidade do acesso cirúrgico à tíbia, no qual a região anatômica favorece a exposição da superfície óssea, não havendo estruturas anatômicas que

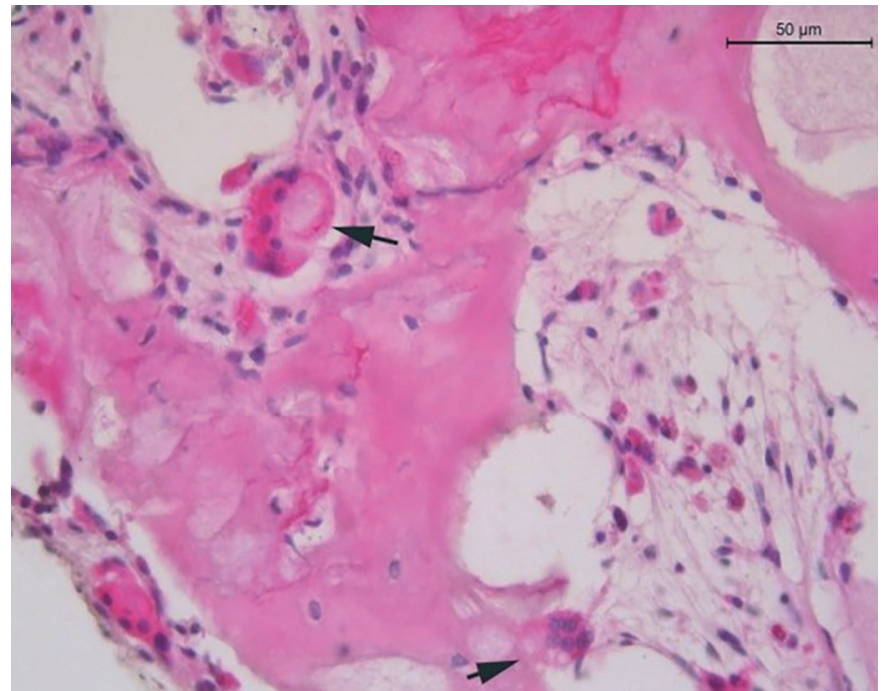

Fig.5. Detalhe do tecido ósseo neoformado no grupo com biomaterial, em que se nota presença de células gigantes multinucleadas, exibindo material exógeno fagocitado (setas pretas). HE, obj.40x.

possam dificultar a avaliação do animal ou a implantação do biomaterial. Esta metodologia já foi descrita e publicada.

No contexto geral referente a implantação do biomaterial, este demonstrou comportamento inerte, no qual os animais se mantiveram estáveis em todo o período pós-operatório, sem alterações nos exames físicos ou impotência funcional dos membros operados, e as feridas cirúrgicas com boa evolução clínica. Ainda, quando introduzido o biomaterial no leito receptor, este não se espalha na superfície óssea, apenas preenche o espaço da falha. A manutenção do preenchimento foi observada no pós-operatório e confirmada no momento da biopsia. Como descrito por Milori et al. (2013) materiais semelhantes ao tecido hospedeiro tendem a apresentar menor resistência mecânica, comparado à implantes metálicos para osteossíntese, por exemplo. Porém o biomaterial deforma-se podendo se adequar 

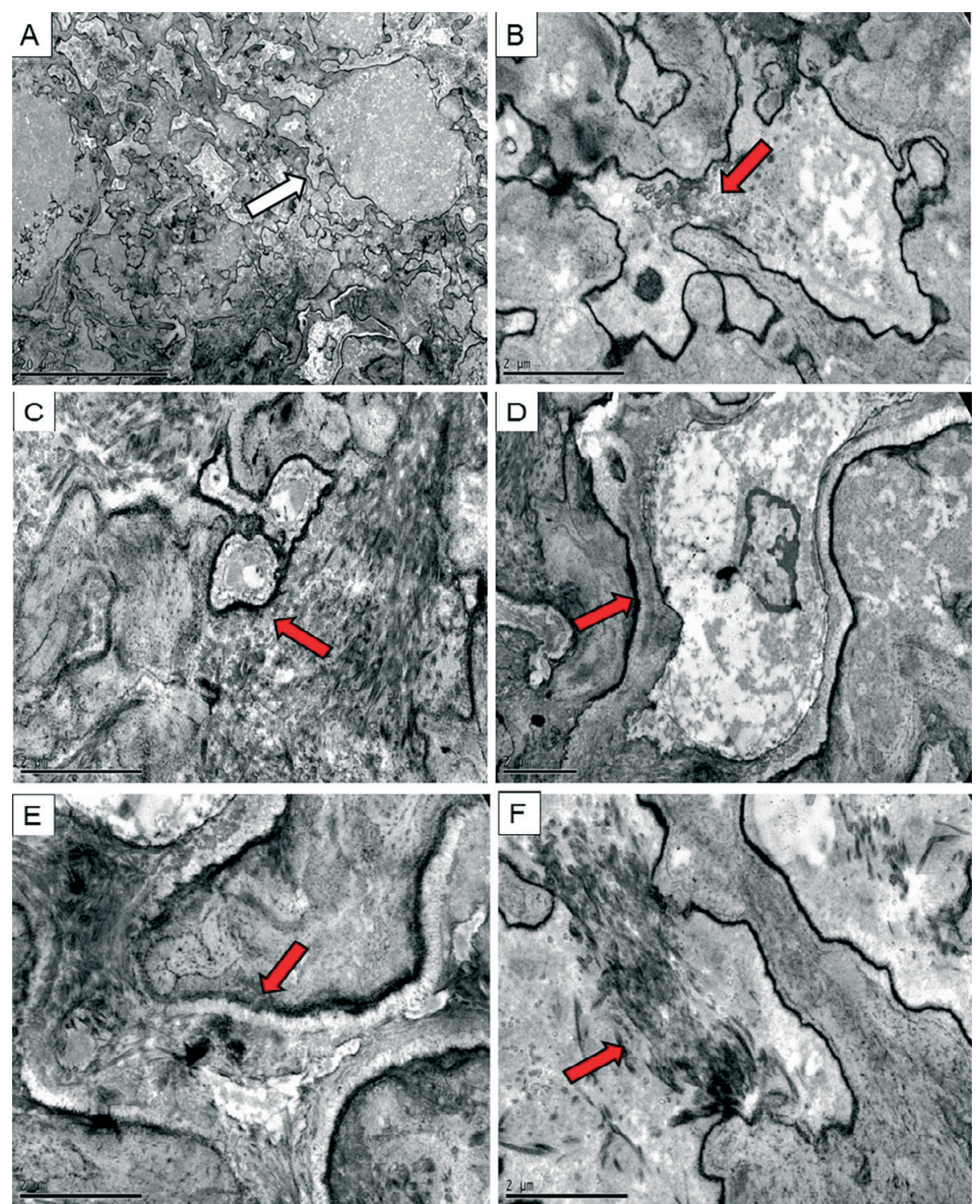

Fig.6. (A) Presença do biomaterial em toda a micrografia; aumento de 3.000x (seta branca). (B) Presença de tecido ósseo neoformado (seta vermelha) envolvido no biomaterial; aumento de $25.000 \mathrm{x}$. (C) Biomaterial entremeado à matriz com imagem sugestiva de presença de proteínas não-colágenas ao redor do biomaterial (seta vermelha); aumento de 25.000x. (D) Presença do biomaterial em contato íntimo com a matriz óssea, "gap" entre o biomaterial e o osteócito (seta vermelha); aumento de 15.000x. (E) Porção inferior de osteócito com presença de canalículos envolvidos na matriz. Observa-se que o biomaterial não dificultou sua formação; aumento de 25.000x. (F) Presença de fibrilas colágenas frouxamente dispostas próximas ao biomaterial (seta vermelha); aumento de $25.000 x$.

e moldar ao defeito ósseo. Esta é uma propriedade atrativa quando na rotina clínica há perda de tecido ósseo, em diferentes tipos de fraturas.

Desta forma, o tamanho do defeito ósseo, embora não seja considerado defeito crítico, possibilitou a avaliação do biomaterial de estudo, implantado, sem interferência de outros implantes. $\mathrm{O}$ incidente com um dos animais, o qual sofreu fratura na altura da falha óssea do membro controle, por ter ocorrido durante a noite, torna impossível a avaliação detalhada da causa e do trauma. Desta forma, sugere-se que a fratura ocorreu nesta localização devido à fragilidade do osso próximo à localização da falha óssea, no entanto este incidente foi considerado um caso isolado, não sendo observado em outros animais.

Embora Martini et al. (2001) ressaltam as particularidades de cada espécie em testes in vivo, com os resultados deste experimento, acredita-se que testes clínicos utilizando este biomaterial como adjuvante à reparação tecidual possa ser indicado. Desta forma, será possível obter mais informações referente a eficácia da osteossíntese com o auxílio deste biomaterial, na rotina ortopédica de animais de grande porte.

$\mathrm{Na}$ análise da microscopia de luz, a presença do tecido ósseo neoformado envolvendo material exógeno (biomate- 
rial) é compatível com a análise ultra estrutural, onde com mais detalhes, também foi possível identificar o tecido ósseo em contato íntimo com o biomaterial de estudo. Nesta última análise, destaca-se a presença de um canalículo entremeado à matriz recém-formada, estrutura fundamental para homeostase do tecido (Andrade et al. 2007). Estas informações sugerem biocompatibilidade, onde a presença do biomaterial não dificulta a formação das estruturas do tecido ósseo. Caso contrário, as evidências de remodelação poderiam estar gravadas na matriz óssea com informações errôneas sobre sua atividade absortiva e formadora (Banks 1992).

Estes dados também estão de acordo com os estudos de Brydone et al. (2010), onde descreveram que a influência dos biomateriais no comportamento celular está diretamente proporcional à melhor osteointegração entre as células teciduais e o biomaterial, e consequentemente, ao efetivo reparo tecidual.

Não foram evidenciados processos inflamatórios ou reação de corpo estranho, porém neste estudo, não é possível afirmar que não tenha ocorrido, pois diferente dos estudos realizados por Almeida et al. (2014), as biopsias ósseas foram realizadas no $60^{\circ}$ dia após o implante, e este evento pode ter ocorrido antes do momento da biopsia. De qualquer forma, independentemente de ter ocorrido, não se observaram alterações evidentes no período pós-operatório, como aumento de sensibilidade dolorosa na região ou claudicação, nem alterações no tecido ósseo, analisado na biopsia.

Embora aparentemente neste estudo, houve maior quantidade de tecido ósseo neoformado no membro controle, este dado não foi representativo estatisticamente. Estas informações estão de acordo com os estudos de Marcondes (2014), no qual a quantificação de matriz orgânica e mineral das amostras com biomaterial também não superou o controle. Acredita-se que isto tenha ocorrido devido à presença do biomaterial nas amostras estudadas, porém, não foi observada diferença quanto à arquitetura tecidual das amostras controle e biomaterial.

A partir deste estudo, analisando e comparando estudos anteriores da mesma linha de pesquisa, e ainda seguindo as diretrizes de Krueger et al. (2012); acredita-se que até o momento, este biomaterial possa ser utilizado em testes clínicos das espécies em foco, isto é, os grandes animais.

\section{CONCLUSÃO}

Com as análises ultra estrutural, qualitativa e quantitativa na avaliação por microscopias foi possível observar interação entre o biomaterial e o tecido ósseo neoformado, sugerindo biocompatibilidade.

Agradecimentos.- Aos membros do grupo de pesquisa Fernanda Silveira Nóbrega, Geissiane de Moraes Marcondes, Luis Eduardo de Almeida, Cinthia Lhamas, Danielle Cristinne Baccarelli, e ao anestesista Douglas do Carmo Alonso; à Fundação de Amparo à Pesquisa do Estado de São Paulo (FAPESP) pela bolsa concedida e o auxílio pesquisa; aos Laboratórios de Patologia Experimental e de Biologia Oral da Faculdade de Odontologia da Universidade de São Paulo; à Escola de Engenharia de São Carlos, Faculdade de Medicina de Ribeirão Preto e Instituto de Química de São Carlos da Universidade de São Paulo.

\section{REFERÊNCIAS}

Almeida L.E.S. 2015. Avaliação biomecânica dos ossos III/IV metacarpianos com falhas ósseas induzidas experimentalmente, tratados com mantas ósseas a base de quitosana, hidroxiapatita e colágeno, em ovinos. Dissertação de Mestrado, Universidade de São Paulo, São Paulo, SP. 81p.

Almeida R.S., Ribeiro I.I.A., Silva M.H.P., Rocha D.N., Miguel F.B. \& Rosa F.P. 2014. Avaliação da fase inicial do reparo ósseo após implantação de biomateriais. Revta Ciênc. Med. Biol. 13:331-336.

Amaral M.B. 2006. Citotoxicidade in vitro e biocompatibilidade in vivo de compósitos a base de hidroxiapatita, colágeno e quitosana. Dissertação de Mestrado, Universidade de São Paulo, São Carlos, SP. 98p.

Andrade A.D., Marinho C.F., Barcelos M., Zorzal M.B. \& Conz M.B. 2007. Biologia óssea: uma revisão da literatura. Implant News 6:659-662.

Babiker H. 2013. Bone graft materials in fixation of orthopaedic implants in sheep. Dan. Med. J. 60:1-15.

Banks W.J. 1992. Tecidos de sustentação: osso, p.137-166. In: Ibid. (Ed.), Histologia Veterinária Aplicada. Manole, São Paulo.

Brydone A.S., Meek D. \& Maclaine S. 2010. Bone grafting, orthopaedic biomaterials, and the clinical need for bone engineering. Proc. Inst. Mech. Eng. H 224:1329-1343.

Carlo C., Borges B., Pacheco A., Rezende D.F., Maria C., Lopes C., César C., Pontes S., Cristine K. \& Duarte S. 2007. Avaliação do efeito osteondutor da hidroxiapatita e do biovidro implantados em tecido subcutâneo de cão. Revta Ceres 316:492-500.

Danilchenko S.N., Kalinkevich O.V., Pogorelov M.V., Kalinkevich A.N., Sklyar A.M., Kalinichenko T.G., Ilyachenko V.Y., Starikov V.V., Bumeyster V.I., Sikora V.Z. \& Sukhodub L.F. 2011. Characterization and in vivo evaluation of chitosan-hydroxyapatite bone scaffolds made by one step coprecipitation method. J. Biomed. Mater. Res. A 96:639-47.

Dantas T.S., Lelis E.R., Naves L.Z., Fernandes-Neto A.J. \& Magalhães D. 2011. Materiais de enxerto ósseo e suas aplicações na odontologia. Unopar Cient. Ciênc. Biol. Saúde 13:131-136.

Dias K.B.D., Silva D.P.S., Ferreira L.A., Fidelis R.R., Costa J.L., Silva A.L.L. \& Scheidt G.N. 2013. Chitin and chitosan: characteristics, uses and production current perspectives. J. Biotec. Biodivers. 4:184-191.

Dornbusch P.T.D., Araujo I.G.R., Tasquetti U.Y., Pimpão C.T., Prado A.M.B. \& Hussni C.A. 2010. Avaliação radiográfica da aplicação do polímero de mamona em falhas ósseas induzidas em equinos. Pesq. Vet. Bras. 15:1-8.

Goissis G. \& Góes J.C. 1997. Géis de colágeno aniônico: ransana como biomateriais, preparação e caracterização físico-química. Polímeros 7:3239.

Gutierres M., Lopes M.A., Hussain N.S., Cabral A.T. \& Almeida L. 2006. Substitutos ósseos conceitos gerais e estado actual. Arq. Med. 19:153-162.

Krueger C.A., Wenke J.C., Masini B.D. \& Stinner D.J. 2012. Characteristics and impact of animal models used for sports medicine research. Orthopedics 35:1410-1415.

Marcondes G.M. 2014. Avaliação da interação biológica entre compósito de quitosana, colágeno e hidroxiapatita e tecido ósseo ovino. Dissertação de Mestrado, Universidade de São Paulo, São Paulo, SP. 175p.

Martini L., Fini M., Giavaresi G. \& Giardino R. 2001. Overview sheep model in orthopedic research: a literature review. CM 51:292-299.

Martins J.V., Perussi M.R., Rossi A.C. \& Freire A.R. 2010. Principais biomateriais utilizados em cirurgia de levantamento de seio maxilar: abordagem clínica. Revta Odontol. Araçatuba 31:22-30.

Milori F.P., Quitzan J., Souza R.S., Cirio S.M., Dornbusch P.T. \& Prado A.M.R.B. 2013. Placas ósseas confeccionadas a partir de diáfise cortical equina na osteossíntese femoral em coelhos. Pesq. Vet. Bras. 33:1201-1207.

Nandi S.K., Roy S., Mukherjee P., Kundu B. \& Basu D. 2010. Orthopaedic applications of bone graft and graft substitutes: a review. Indian J. Med. Res. 132:15-30.

Nóbrega F.S. 2014. Avaliação da interação biológica entre o polímero de poliuretana de mamona acrescido de carbonato de cálcio e tecido ósseo de equinos. Tese de Doutorado, Universidade de São Paulo, São Paulo, SP. $156 p$. 
Paretsis N.F., Baccarelli D.C., Lhamas C. L., Alonso D.C., Nóbrega F.S. \& Zoppa A.L.V. 2016. Ostectomia de tíbia em modelo experimental ovino para estudo de regeneração óssea. Ars Vet. 32:1-8

Pearce A.I., Ricchards R.G., Milz S., Schneider E. \& Pearce S.G. 2007. Animal models for implant biomaterial research in bone: a review. Eur. Cell Mater. 13:1-10.

Pettian M.S., Santos G.R., Lenise P., Pleppis A.M.G., Martins V.C.A. \& Cunha M. R. 2014. Capacidade osteogênica de colágeno derivada da serosa do intestino bovino no tratamento de falhas ósseas provocadas no crânio de ratos. Anais Congresso Brasileiro Engenharia Biomédica, Uberlândia, p.97-100.

Raggatt L.J. \& Partridge N.C. 2010. Cellular and molecular mechanisms of bone remodeling. J. Biol. Chem. 285:25103-25108.

Reis E.C.C., Borges A.P.B., Fonseca C.C., Martinez M.M.M., Eleotério R.B., Morato G.O. \& Oliveira P.M. 2010. Biodegradation of a hydroxyapatite-polyhydroxybutyrate composite. Braz. Arch. Biol. Technol. 53:817-826.
Shirane H.Y., Oda D.Y., Pinheiro T.C. \& Cunha M.R. 2010. Implantes de biomateriais em falha óssea produzida na fíbula de ratos. Revta Bras. Ortop. 45:478-482

Spin-Neto R., Coletti F.L., Freitas R.M., Pavone C., Campana-Filho S.P. \& Marcantonio R.A. C. 2012. Chitosan-based biomaterials used in critical-size bone defects: radiographic study in rat's calvaria. Revta Odontol. Unesp 41:312-317.

Tavakol S., Nikpour M.R., Amani A., Soltani M., Rabiee S.M., Rezayat S.M., Chen P. \& Jahanshahi M. 2013. Bone regeneration based on nano-hydroxyapatite and hydroxyapatite/chitosan nanocomposites: an in vitro and in vivo comparative study. J. Nanopart. Res. 15:1-16.

Vital C.C., Borges A.P.B., Fonseca C.C., Tsiomis A.C., Carvalho T.B., Fontes E.B., Sena M.P. \& Fófano G. 2006. Biocompatibilidade e comportamento de compósitos de hidroxiapatita em falha óssea na ulna de coelhos. Arq. Bras. Medi. Vet. Zootec. 58:175-183. 